\title{
Oral Manifestations of Systemic Lupus Erythematosus Patients in Qatar: A Pilot Study
}

\author{
Mohammed Hammoudeh (DD, ${ }^{1}$ Ahmed Al-Momani, ${ }^{2}$ Husam Sarakbi, \\ Prem Chandra $\left(\mathbb{D}^{3},{ }^{3}\right.$ and Samer Hammoudeh $\mathbb{1}^{4}$ \\ ${ }^{1}$ Department of Medicine, Hamad Medical Corporation, P.O. Box 3050, Doha, Qatar \\ ${ }^{2}$ Department of Dentistry, Hamad Medical Corporation, P.O. Box 3050, Doha, Qatar \\ ${ }^{3}$ Medical Research Center, Hamad Medical Corporation, P.O. Box 3050, Doha, Qatar \\ ${ }^{4}$ Research Department, Weill Cornell Medicine-Qatar, P.O. Box 24144, Doha, Qatar
}

Correspondence should be addressed to Mohammed Hammoudeh; mhamoudeh@hamad.qa

Received 7 December 2017; Revised 11 February 2018; Accepted 11 March 2018; Published 10 April 2018

Academic Editor: Charles J. Malemud

Copyright (c) 2018 Mohammed Hammoudeh et al. This is an open access article distributed under the Creative Commons Attribution License, which permits unrestricted use, distribution, and reproduction in any medium, provided the original work is properly cited.

Objective. The purpose of this pilot study was to assess the prevalence of oral manifestations among systemic lupus erythematosus (SLE) patients in Qatar, in order to warrant future studies that would investigate each one of these manifestations with detail and further scrutiny. Methods. Study procedures took place between November 2014 and April 2016. All patients visiting the outpatient rheumatology clinics at Hamad General Hospital, Doha, Qatar, were asked to join. The American College of Rheumatology (ACR) 1997 criteria of SLE were used. The patients were examined initially by a rheumatologist and were later scheduled for an appointment with a dentist at the same institution. A total of 77 patients were recruited for the study. Results. Prevalence rates for the different oral manifestations ranged from $2.4 \%$ for soft palate ulcers, cheilitis, and oral candida to $88.1 \%$ for the presence of cavitation. Gingivitis, periodontal disease, cavities, and missing teeth were observed in more than $50 \%$ of the sample. The prevalence of periodontal disease and missing teeth was higher among those with an SLE duration $>8$ years. On the contrary, the prevalence of gingivitis and cavities was higher among those with an SLE duration $\leq 8$ years. Conclusion. This study found high rates of gingivitis, periodontal disease, cavities, and missing teeth among SLE patients in Qatar. It is recommended that healthcare providers of such patients monitor the presence of any oral manifestations in order to arrange for early treatment and prevention efforts. Future prospective longitudinal studies with adequate sample size and power are needed in order to ascertain any causation factors or common etiology pathways.

\section{Background}

Systemic lupus erythematosus (SLE) is a chronic autoimmune inflammatory disease which involves the connective tissue [1-3]. Several organs are also involved such as the brain, lungs, kidneys, heart, blood vessels, muscles, and skin [4]. SLE is more common among women [5-7], with a common onset between 15 and 40 years of age [4]. Researchers reported a prevalence rate of $30-50$ cases per every 100,000 , while incidence rates ranged from 0.9 to $3.1 \%$ among every 100,000 per year, among Asian populations [8]. In Saudi Arabia, a prevalence rate of 19.28 per 100,000 has been reported [9]. Globally, a prevalence rate of $12-50$ cases per every 100,000 has been reported [10], while an incidence rate ranging from
0.3 in Ukraine to 11 in Australia cases per every 100,000 has been reported [11]. Common symptoms of SLE include fever, weight loss, glomerulonephritis, alopecia, rash, and vesiculobullous lesions [12]. Other manifestations such as arthralgia and arthritis are frequently seen, with migratory arthritis affecting about $75 \%$ of patients [4].

Oral manifestations of SLE are frequently encountered [13] and may include oral ulceration, honeycomb plaque, raised keratotic plaque, nonspecific erythema, purpura, petechiae, and cheilitis [14]. Research shows that 25\% of SLE patients have oral mucous membrane and lip involvement with possible petechiae. Both xerostomia and hyposalivation predispose patients with SLE to dental caries and recurrent noninfectious pharyngitis and oral ulcerations. Oral 
candidiasis and infections are also common due to the usage of corticosteroid which is used in the treatment of SLE [4]. The most common oral manifestation reported to be present among SLE patients is oral ulcerations [3], with a prevalence rate ranging between 7 and $41 \%$, which is observed to be more severe as the disease [15]. Others reported a prevalence rate of $8-45 \%$ for oral lesions among SLE [16].

A study conducted in Venezuela on 90 systemic and cutaneous lupus erythematosus patients reported that $11 \%$ had oral lesions including oral ulcerations, erythema, and white plaque [17]. A study conducted in Saudi Arabia on 46 SLE patients reported mucocutaneous involvement including oral ulcers in $72 \%$ and discoid lupus in $13 \%$ of the sample [18].

Among the oral manifestations is periodontal disease (PD), which is an infection of the tissue supporting and surrounding tooth structure [19]. Sales et al. showed that a relationship does exist between SLE activity and periodontal status, along with a relationship between the latter and levels of CRP in serum [20]. In an earlier study, Rhodus and Johnson showed a high prevalence of oral lesions among SLE patients, including angular cheilitis, ulcers, mucositis, and glossitis. A high prevalence of oral complaints such as dysphagia, dysgeusia, and glossodynia was also present [15]. A recent systematic review reported a significant association between periodontitis and SLE [13].

Fabbri et al. showed that treatment of periodontal disease among SLE patients on immunosuppressive therapy is beneficial in controlling disease activity [21]. A more recent study as well showed that treatment of periodontal disease aids in reducing the symptoms of SLE [22].

On the contrary, Mutlu et al. showed no significant difference in periodontal probing depths between SLE patients and healthy controls, yet concluding the absence of any evidence that points toward higher predisposition of SLE patients to periodontal involvement [23]. A recent review reported conflicting results as well [24]. Al-Mutairi reported no significant difference in periodontal findings between 25 SLE patients and 50 healthy controls. Among those with SLE, no correlation was found between SLE biomarkers and their periodontal findings [25].

The purpose of this study was to assess the prevalence of oral manifestations among systemic lupus erythematosus patients in Qatar in order to warrant future studies that would investigate each one of these manifestations with detail and further scrutiny.

\section{Materials and Methods}

The study took place between November 2014 and April 2016. All patients visiting the outpatient rheumatology clinics at Hamad General Hospital, Doha, Qatar, were asked to participate. A waiver of consent form was obtained from the IRB at the same institution, which also provided IRB approval for the study (14301/14). The inclusion criteria for the study included subjects (a) meeting the American College of Rheumatology (ACR) 1997 criteria of SLE, (b) willing to participate in the study, and (c) able to tolerate study oral and dental examination procedures. The exclusion criteria excluded subjects who (a) did not meet the 1997 ACR criteria of SLE, (b) were unwilling to participate in the study, and (c) were unable to tolerate study oral and dental examination procedures. The patients were examined initially by a rheumatologist and were later scheduled for an appointment with the same dentist at the same institution, for an oral and dental examination.

The rheumatologist consented subjects checked that they meet the ACR 1997 criteria for SLE and recorded the following information: date of diagnosis, the presence of any comorbid conditions, the status of disease activity on the date of the examination based on clinical and serological data, medications, demographic, and education level. A clinical oral and calibrated periodontal exam was done by the same dentist. The dentist was requested to document the following oral manifestations on a data collection sheet that was designed for the study: soft and hard palate ulcers, ecchymosis, petechiae, lupus mucosae oris, cheilitis, candida, discoid, herpes simplex, gingivitis, periodontal disease, cavities, and missing teeth. No biopsy was taken. A total of 77 patients were recruited for the study. Only 42 patients appeared for their dental appointments. The findings in those 42 patients are presented and discussed in this publication.

2.1. Statistical Analysis. Anonymous data were collected and entered into a standard electronic database designed in view of study design and objectives. Descriptive statistics were used to summarize all demographic, clinical, and other characteristics of the participants. The primary outcome variable was to assess and estimate the prevalence of oral manifestations among systemic lupus erythematosus patients among the population in Qatar, and this was estimated and tested using appropriate $Z$ test and the corresponding 95\% CI was computed to measure the precision of the prevalence estimate. The prevalence of different oral manifestations (\%) was calculated by dividing the total number of oral manifestation cases (prevalent cases) by the total number of participants included. Associations between two or more qualitative variables (gender, different oral manifestations with dichotomous categories of disease duration, etc.) were assessed using chisquare $\left(\chi^{2}\right)$ test, Fisher Exact test, and/or Yates corrected chisquare as appropriate. Quantitative variables (age, SLE duration, etc.) means between the two independent groups (SLE active and inactive groups) were analyzed using unpaired " $t$ " test or Mann-Whitney $U$ test as appropriate. Pictorial presentations of the key results were made using appropriate statistical graphs. All $P$ values presented were two-tailed, and $P$ values $<0.05$ were considered as statistically significant. All Statistical analyses were done using statistical packages SPSS 22.0 (SPSS Inc., Chicago, IL) and Epi-info (Centers for Disease Control and Prevention, Atlanta, GA) software.

\section{Results}

The sample had a mean age of $38.31 \pm 10.65$ years and was mainly comprised of females, with a female to male ratio of 9.5 to 1 . Table 1 summarizes other demographic and medical data. 
TABLE 1: Demographic and medical data of the study sample.

\begin{tabular}{|c|c|c|}
\hline & $N$ & $\%$ \\
\hline \multicolumn{3}{|l|}{ Age (years) } \\
\hline $18-29$ & 11 & 26.2 \\
\hline $30-49$ & 25 & 59.5 \\
\hline$\geq 50$ & 6 & 14.3 \\
\hline \multicolumn{3}{|l|}{ Gender } \\
\hline Male & 4 & 9.5 \\
\hline Female & 38 & 90.5 \\
\hline \multicolumn{3}{|l|}{ Education } \\
\hline High school & 16 & 38.1 \\
\hline University & 26 & 61.9 \\
\hline \multicolumn{3}{|l|}{ SLE duration } \\
\hline$\leq 8$ years & 21 & 50.0 \\
\hline$>8$ years & 21 & 50.0 \\
\hline \multicolumn{3}{|l|}{ SLE activity } \\
\hline Active & 8 & 19.0 \\
\hline Inactive & 34 & 81.0 \\
\hline \multicolumn{3}{|l|}{ On steroids } \\
\hline No & 18 & 42.9 \\
\hline \multicolumn{3}{|l|}{ Yes } \\
\hline $1-10 \mathrm{mg}$ & 20 & 47.6 \\
\hline $11-30 \mathrm{mg}$ & 3 & 7.1 \\
\hline$\geq 31$ & 1 & 2.4 \\
\hline \multicolumn{3}{|c|}{ On immunosuppressant } \\
\hline Yes & 15 & 35.7 \\
\hline No & 27 & 64.3 \\
\hline \multicolumn{3}{|l|}{ Dry mouth } \\
\hline Yes & 14 & 33.3 \\
\hline No & 28 & 46.7 \\
\hline
\end{tabular}

Four oral manifestations were observed in more than half of the study sample: gingivitis, periodontal disease, cavitation, and missing teeth. A summary of other oral manifestations is listed in Table 2.

The dental examination revealed that $54.8 \%$ (95\% CI 39.9, 68.8 ) of the study sample had a form of gingivitis, of which more of those with an SLE duration of $\leq 8$ years (62\% versus $48 \%$ ) had gingivitis $(P=0.352)$. Localized gingivitis was found more commonly among those with an SLE duration of $\leq 8$ years ( $57 \%$ versus $38 \%$ ); however this difference was noted to be statistically insignificant $(P=0.448)$. Figure 1 displays the number of cases with gingivitis as well as the type.

Furthermore, periodontal disease was observed in 57.1\% of the study sample. The presence of periodontal disease and type was compared between those with an SLE duration of $\leq 8$ years and those $>8$ years as shown in Figure 2 . Significantly higher participants with an SLE duration $>8$ years had periodontal disease compared to those with SLE duration $\leq 8$ years $(81 \%$ versus $33 \% ; P=0.002)$. Localized periodontal disease was found more commonly among those with an SLE duration of $>8$ years ( $43 \%$ versus $33 \%, P=0.119$ ).

Finally, $88.1 \%$ of the sample had cavities, while $64.3 \%$ had missing teeth. Figure 3 compares those with an SLE duration
TABLE 2: A summary of oral manifestations of the study sample.

\begin{tabular}{|c|c|c|}
\hline & $N$ & $\%(95 \% \mathrm{CI})$ \\
\hline \multicolumn{3}{|c|}{ Hard palate ulcer } \\
\hline Yes & 2 & $4.8(1.3,15.8)$ \\
\hline No & 40 & $95.2(84.2,98.7)$ \\
\hline \multicolumn{3}{|c|}{ Soft palate ulcer } \\
\hline Yes & 1 & $2.4(0.43,12.59)$ \\
\hline No & 41 & $97.6(87.7,99.6)$ \\
\hline \multicolumn{3}{|l|}{ Ecchymosis } \\
\hline Yes & 0 & $0(0,8.38)$ \\
\hline No & 42 & $100.0(91.6,100)$ \\
\hline \multicolumn{3}{|l|}{ Petechiae } \\
\hline Yes & 7 & $16.7(8.32,30.6)$ \\
\hline No & 35 & $83.3(69.4,91.7)$ \\
\hline \multicolumn{3}{|c|}{ Lupus mucosae oris } \\
\hline Yes & 0 & $0(0,8.38)$ \\
\hline No & 42 & $100.0(91.6,100)$ \\
\hline \multicolumn{3}{|l|}{ Cheilitis } \\
\hline Yes & 1 & $2.4(0.43,12.59)$ \\
\hline No & 41 & $97.6(87.7,99.6)$ \\
\hline \multicolumn{3}{|l|}{ Candida } \\
\hline Yes & 1 & $2.4(0.43,12.59)$ \\
\hline No & 41 & $97.6(87.7,99.6)$ \\
\hline \multicolumn{3}{|l|}{ Discoid } \\
\hline Yes & 0 & $0(0,8.38)$ \\
\hline No & 42 & $100.0(91.6,100)$ \\
\hline \multicolumn{3}{|c|}{ Herpes simplex } \\
\hline Yes & 0 & $0(0,8.38)$ \\
\hline No & 42 & $100.0(91.6,100)$ \\
\hline \multicolumn{3}{|l|}{ Gingivitis } \\
\hline Yes & 23 & $54.8(39.9,68.8)$ \\
\hline No & 19 & $45.2(31.2,60.1)$ \\
\hline \multicolumn{3}{|c|}{ Gingivitis type } \\
\hline Localized & 20 & $47.6(33.4,62.3)$ \\
\hline Generalized & 3 & $7.1(2.5,19.1)$ \\
\hline \multicolumn{3}{|c|}{ Periodontal disease } \\
\hline Yes & 24 & $57.1(42.2,70.9)$ \\
\hline No & 18 & $42.9(29.1,57.8)$ \\
\hline \multicolumn{3}{|c|}{ Periodontal disease type } \\
\hline Localized & 16 & $38.1(25.0,53.2)$ \\
\hline Generalized & 8 & $19.0(9.9,33.3)$ \\
\hline \multicolumn{3}{|l|}{ Cavities } \\
\hline Yes & 37 & $88.1(75.0,94.8)$ \\
\hline No & 5 & $11.9(5.2,25.0)$ \\
\hline \multicolumn{3}{|l|}{ Missing teeth } \\
\hline Yes & 27 & $64.3(49.2,77.0)$ \\
\hline No & 15 & $35.7(22.9,50.8)$ \\
\hline
\end{tabular}

CI: confidence interval.

$\leq 8$ years and those with $>8$ years, in regard to cavities $(90.5 \%$ versus $85.7 \%, P=0.634)$ and missing teeth $(61.9 \%$ versus $66.7 \%, P=0.747)$. 


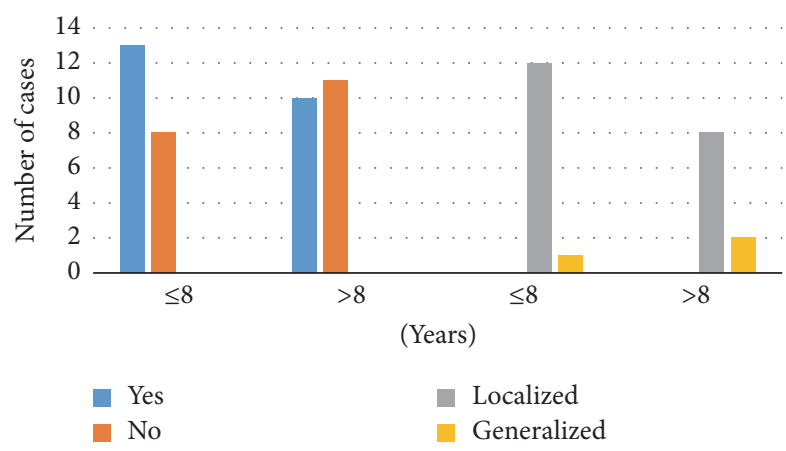

FIgURE 1: Number of cases and type of gingivitis.

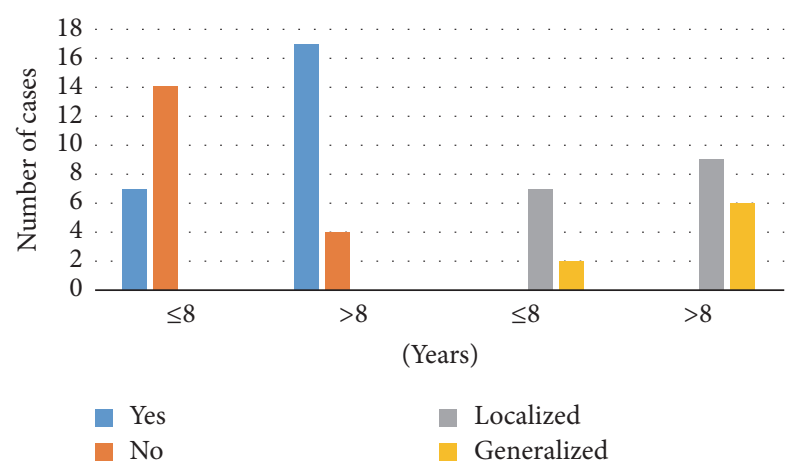

Figure 2: Number of cases and type of periodontal disease.

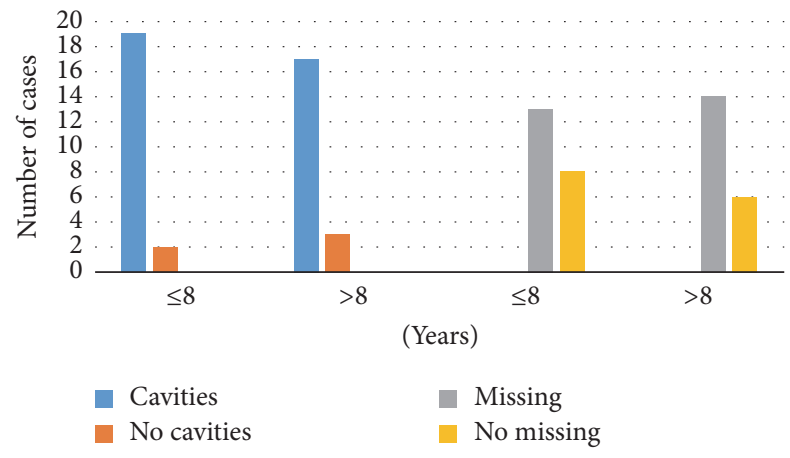

FIgURE 3: Number of cases with cavities and missing teeth.

\section{Discussion}

The current study investigated the presence of oral manifestations among SLE patients in Qatar. The mean age of our study sample was $38.3 \pm 10.6$ years, and the mean disease duration was $9.4 \pm 6.6$ years. A study conducted in Saudi Arabia on 624 SLE patients reported a mean age of $34.3 \pm 11.9$ years, and a mean disease duration of $9.3 \pm 5.3$ years [26]. The LUMINA cohort reported a mean age of $37.3 \pm 12.8$ years, and a mean disease duration of $20 \pm 17$ months [27].

The female to male ratio in our study was $9.5: 1$. This is similar to the ratio reported in China 9.6:1 [28], in Saudi Arabia 9.8:1 [26], or in the Euro-Lupus cohort $10: 1$ [5]. Lower ratios were reported in Spain $8: 1$ [29] and in Iran $6.5: 1$ [30].
The results of our study showed varying prevalence rates for the different oral manifestations, ranging from $2.4 \%$ for soft palate ulcers, cheilitis, and oral candida to $88.1 \%$ for the presence of cavities. Soft palate ulcers are one of the criteria for diagnosing SLE and are usually found more commonly in patients with active disease. A study in Iran reported that $54 \%$ of the 188 SLE patients had oral mucosal lesions, with the ulcer being the most prevalent (28\%) [31]. More than $80 \%$ of the 16 SLE patients in another study were reported to have oral manifestations [15]. We had a low rate of oral ulcers in our study, most likely because only $8 / 42$ of the patients were having active disease during the examination.

The results of this study also showed a prevalence rate of $57.1 \%$ for periodontal disease (localized $38.1 \%$, generalized $19 \%)$. A study conducted in Saudi Arabia reported that there was no difference in periodontal parameters between 25 SLE patients and 50 healthy controls [25]. Another Saudi study reported a $68 \%$ prevalence rate of periodontitis, among a sample of 282 of Saudi dental school patients. The localized form of periodontitis was present in $28 \%$ of the sample, while the generalized form was present in $40 \%$ [32]. A study conducted in Japan reported a 70\% prevalence rate of periodontitis among SLE patients compared to 30\% among the general population [33]. An older case report involving a patient with active SLE reported that the patient suffered from severe and generalized gingival recession and periodontal involvement [34]. An older study showed that 93.8\% of SLE patients had periodontitis [15].

Furthermore, $64.3 \%$ of the sample of this study had missing teeth. A study conducted in Brazil recently showed a higher rate of missing teeth among 75 SLE patients compared to 78 participants without SLE. However, no differences were found between the two groups in regard to the presence of periodontitis, decayed and/or filled teeth in the same study [35]. Moreover, $88.1 \%$ of our study sample had cavities, which comes concurrent with a recent study conducted in Mexico which reported that $85 \%$ of the 60 SLE patients had cavities, with the rate reaching $100 \%$ among those with active disease [36].

Among the challenges that this study faced was the scarcity of SLE patients. In addition, due to the nature of the disease, majorly being dominant by females, a very low number of male patients were recruited for this study, which did not allow for comparisons based on gender. Among the disadvantages, due to the small sample size, it would be difficult to generalize any of the results obtained in this study to other SLE patients in Qatar or in the region.

Future studies will need to be multicenter studies in order to secure a larger sample size. Additionally, we were not able to compare to a control group, which would be a good idea to include in future studies. Finally, longitudinal studies are needed in order to ascertain any causation factors or common etiology pathways.

In regard to recommendations, researchers recommend examining mucosal changes, periodontal inflammation and bleeding, and overall dentition of systemic diseases such as SLE, as it would allow for early detection and treatment [14, 31]. Healthcare providers are also recommended to monitor infections of the head and neck to avoid further progression 
of any possible infection due to the higher predisposition to complications because of immunosuppressive treatment received [10].

\section{Conclusion}

This pilot study found high rates of gingivitis, periodontal disease, cavities, and missing teeth among SLE patients in Qatar. It is recommended that healthcare providers of such patients monitor the presence of any oral manifestations in order to arrange for early treatment. Future longitudinal studies are needed in order to ascertain any causation factors or common etiology pathways.

\section{Abbreviations}

ACR: American College of Rheumatology

PD: Periodontal disease

SLE: Systemic lupus erythematosus.

\section{Conflicts of Interest}

The authors declare that they have no conflicts of interest.

\section{References}

[1] T. J. A. Lehman, "A practical guide to systemic lupus erythematosus," Pediatric Clinics of North America, vol. 42, no. 5, pp. 1223-1238, 1995.

[2] E. M. Tan, A. S. Cohen, J. F. Fries et al., "The 1982 revised criteria for the classification of systemic lupus erythrematosus," Arthritis \& Rheumatology, vol. 25, no. 11, pp. 1271-1277, 1982.

[3] G. C. Tsokos, "Systemic lupus erythematosus," The New England Journal of Medicine, vol. 365, no. 22, pp. 2110-2121, 2011.

[4] G. Atherley and L. Taylor, "College of Dental Hygienists of Ontario Advisory Lupus," 2012, http://www.cdho.org/Advisories/CDHO_Advisory_Lupus.pdf.

[5] R. Cervera, M. A. Khamashta, J. Font et al., "Systemic lupus erythematosus: clinical and immunologic patterns of disease expression in a cohort of 1,000 patients, The European Working Party on Systemic Lupus Erythematosus," Medicine, vol. 72, no. 2, pp. 113-124, 1993.

[6] J. J. Condemi, “The Autoimmune Diseases," Journal of the American Medical Association, vol. 258, no. 20, pp. 2920-2929, 1987.

[7] J. M. von Feldt, "Systemic lupus erythematosus. Recognizing its various presentations," Postgraduate Medical Journal, vol. 97, no. 4, pp. 79-86, 1995.

[8] C. Sing Lau, E. Osio-Salido, and H. Manapat-Reyes, "Epidemiology of systemic lupus erythematosus in Asia," Lupus, vol. 19, no. 12, pp. 1365-1373, 2010.

[9] A. S. Al-Arfaj, S. R. Al-Balla, A. N. Al-Dalaan et al., "Prevalence of systemic lupus erythematosus in central Saudi Arabia," Saudi Medical Journal, vol. 23, no. 1, pp. 87-89, 2002.

[10] J. B. Albilia, D. K. Lam, C. M. Clokie, and G. K. Sandor, "Systemic lupus erythematosus: a review for dentists," Journal of the Canadian Dental Association, vol. 73, no. 9, pp. 823-828, 2007.

[11] M. Scolnik, J. Marin, S. M. Valeiras, M. F. Marchese, A. S. Talani, and N. L. Avellaneda, "Incidence and prevalence of lupus in
Buenos Aires," Lupus Science \& Medicine, vol. 1, no. 1, Article ID e000021, p. 10, 2014.

[12] S. M. Burge, P. A. Frith, R. P. Juniper, and F. Wojnarowska, "Mucosal involvement in systemic and chronic cutaneous lupus erythematosus," British Journal of Dermatology, vol. 121, no. 6, pp. 727-741, 1989.

[13] Z. Rutter-Locher, T. O. Smith, I. Giles, and N. Sofat, "Association between Systemic Lupus Erythematosus and Periodontitis: A Systematic Review and Meta-analysis," Frontiers in Immunology, vol. 8, 2017.

[14] A. C. Chi, B. W. Neville, J. W. Krayer, and W. C. Gonsalves, "Oral manifestations of systemic disease," American Family Physician, vol. 82, no. 11, pp. 1381-1388, 2010.

[15] N. L. Rhodus and D. K. Johnson, "The prevalence of oral manifestations of systemic lupus erythematosus," Quintessence International, vol. 21, no. 6, pp. 461-465, 1990.

[16] M. Schiodt, "Oral manifestations of lupus erythematosus," International Journal of Oral Surgery, vol. 13, no. 2, pp. 101-147, 1984.

[17] J. López-Labady, M. Villarroel-Dorrego, N. González, R. Pérez, and et al., "Oral manifestations of systemic and cutaneous lupus erythematosus in a Venezuelan population," Journal of Oral Pathology \& Medicine, vol. 36, no. 9, pp. 524-527, 2007.

[18] N. Abid, A. S. Khan, and F. H. A. Otaibi, "Systemic lupus erythematosus (SLE) in the eastern region of Saudi Arabia. A comparative study," Lupus, vol. 22, no. 14, pp. 1529-1533, 2013.

[19] W. Nesse, P. U. Dijkstra, F. Abbas et al., "Increased prevalence of cardiovascular and autoimmune diseases in periodontitis patients: A cross-sectional study," Journal of Periodontology, vol. 81, no. 11, pp. 1622-1628, 2010.

[20] L. d. A. R. Sales, S. Vassalo, M. d. G. A. M. Chaves, and F. M. Aarestrup, "Periodontal disease and systemic lupus erythematosus activity," Revista Interdisciplinar de Estudos Experimentais, vol. 1, no. 1, pp. 14-20, 2009.

[21] C. Fabbri, R. Fuller, E. Bonfa, L. K. Guedes, P. S. D’Alleva, and E. F. Borba, "Periodontitis treatment improves systemic lupus erythematosus response to immunosuppressive therapy," Clin Rheumatol, vol. 33, no. 4, pp. 505-509, 2014.

[22] C. P. Marques, Y. Maor, M. S. de Andrade, V. P. Rodrigues, and B. B. Benatti, "Possible evidence of systemic lupus erythematosus and periodontal disease association mediated by Toll-like receptors 2 and 4," Clinical \& Experimental Immunology, vol. 183, pp. 187-192, 2016.

[23] S. Mutlu, A. Richards, P. Maddison, and C. Scully, "Gingival and periodontal health in systemic lupus erythematosus," Community Dentistry and Oral Epidemiology, vol. 21, no. 3, pp. 158-161, 1993.

[24] D. C. Calderaro, G. A. Ferreira, S. M. S. de Mendonça et al., "Is there an association between systemic lupus erythematosus and periodontal disease?" Revista Brasileira de Reumatologia, vol. 56, no. 3, pp. 280-284, 2016.

[25] K. D. Al-Mutairi, M. S. Al-Zahrani, S. M. Bahlas, R. A. Kayal, and K. H. Zawawi, "Periodontal findings in systemic lupus erythematosus patients and healthy controls," Saudi Medical Journal, vol. 36, no. 4, pp. 463-468, 2015.

[26] A. S. Al Arfaj and N. Khalil, "Clinical and immunological manifestations in 624 SLE patients in Saudi Arabia," Lupus, vol. 18 , no. 5, pp. 465-473, 2009.

[27] G. S. Alarcon, A. W. Friedman, K. V. Straaton et al., "Systemic lupus erythematosus in three ethnic groups: III. A comparison of characteristics early in the natural history of the LUMINA cohort," Lupus, vol. 8, no. 3, pp. 197-209, 1999. 
[28] J. Wang, S. Yang, J. J. Chen et al., "Systemic lupus erythematosus: a genetic epidemiology study of 695 patients from China," Archives of Dermatological Research, vol. 298, no. 10, pp. 485491, 2007.

[29] J. Font, R. Cervera, M. Ramos-Casals et al., "Clusters of Clinical and Immunologic Features in Systemic Lupus Erythematosus: Analysis of 600 Patients from a Single Center," Seminars in Arthritis and Rheumatism, vol. 33, no. 4, pp. 217-230, 2004.

[30] M. A. Nazarinia, F. Ghaffarpasand, A. Shamsdin, A. A. Karimi, N. Abbasi, and A. Amiri, "Systemic lupus erythematosus in the Fars Province of Iran," Lupus, vol. 17, no. 3, pp. 221-227, 2008.

[31] M. Khatibi, A. H. Shakoorpour, Z. M. Jahromi, and A. Ahmadzadeh, "The prevalence of oral mucosal lesions and related factors in 188 patients with systemic lupus erythematosus," Lupus, vol. 21, no. 12, pp. 1312-1315, 2012.

[32] M. S. Al-Zahrani and R. A. Kayal, "Alveolar bone loss and reported medical status among a sample of patients at a Saudi dental school," Oral Health \& Preventive Dentistry, vol. 4, no. 2, pp. 113-118, 2006.

[33] T. Kobayashi, S. Ito, K. Yamamoto et al., "Risk of periodontitis in systemic lupus erythematosus is associated with $\mathrm{F} c \gamma$ receptor polymorphisms," Journal of Periodontology, vol. 74, no. 3, pp. 378-384, 2003.

[34] R. M. Nagler, M. Lorber, Y. Ben-Arieh, D. Laufer, and S. Pollack, "Generalized periodontal involvement in a young patient with systemic lupus erythematosus," Lupus, vol. 8, no. 9, pp. 770-772, 1999.

[35] J. D. Corrêa, L. G. Branco, D. C. Calderaro et al., "Impact of systemic lupus erythematosus on oral health-related quality of life," Lupus, vol. 27, no. 2, pp. 283-289, 2017.

[36] J. P. Loyola Rodriguez, L. J. Galvan Torres, R. E. Martinez Martinez et al., "Frequency of dental caries in active and inactive systemic lupus erythematous patients: Salivary and bacterial factors," Lupus, vol. 25, no. 12, pp. 1349-1356, 2016. 


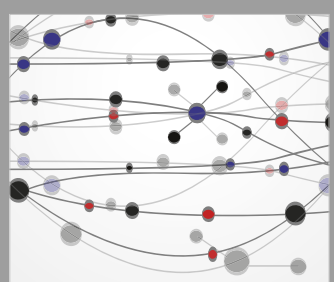

The Scientific World Journal
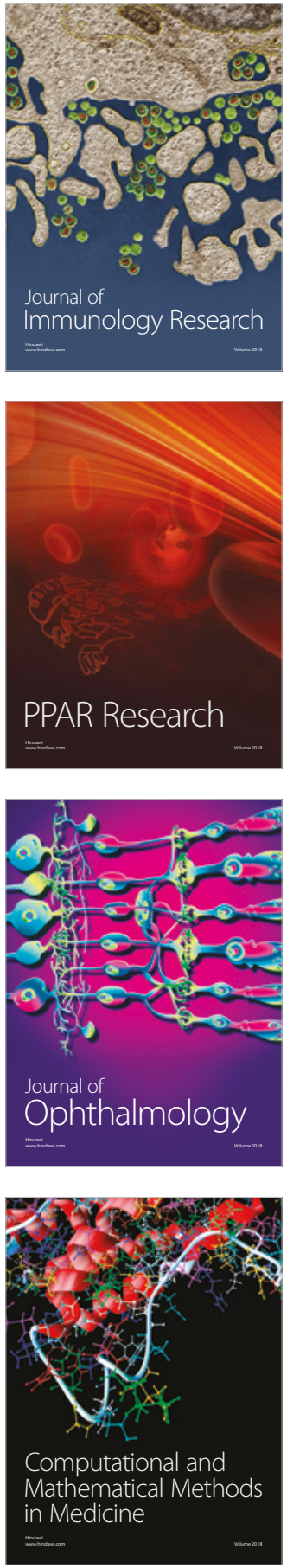

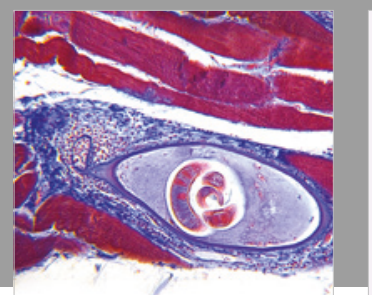

Gastroenterology Research and Practice

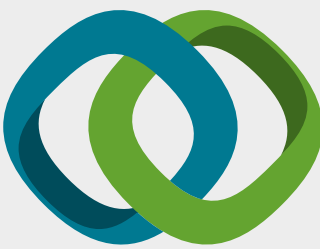

\section{Hindawi}

Submit your manuscripts at

www.hindawi.com
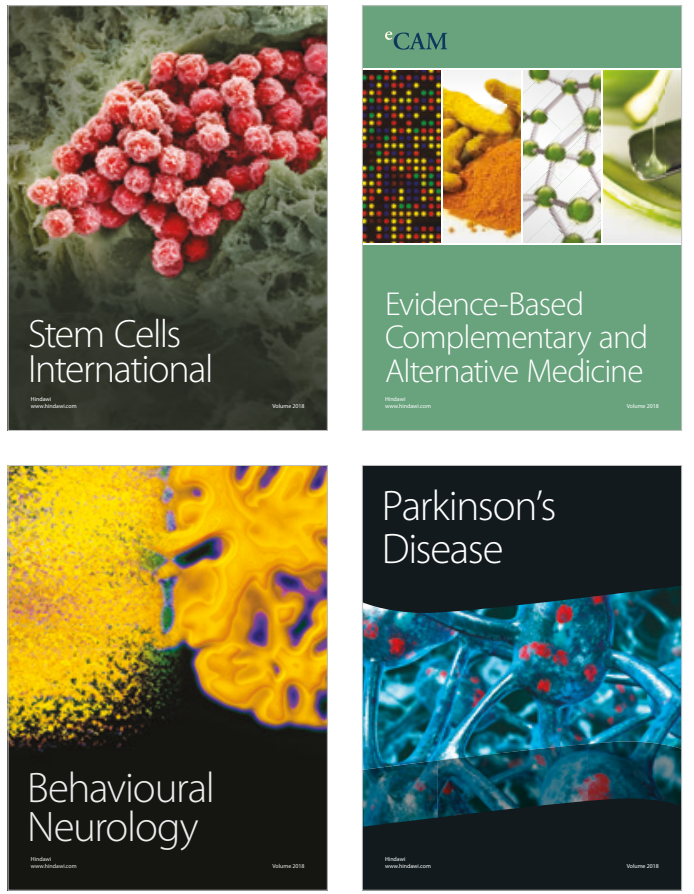

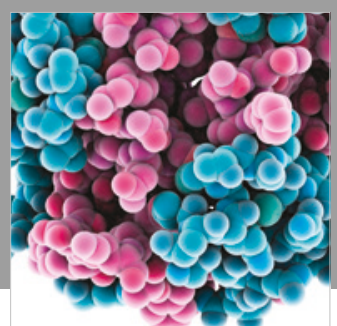

ournal of

Diabetes Research

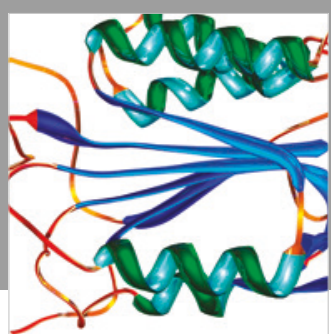

Disease Markers
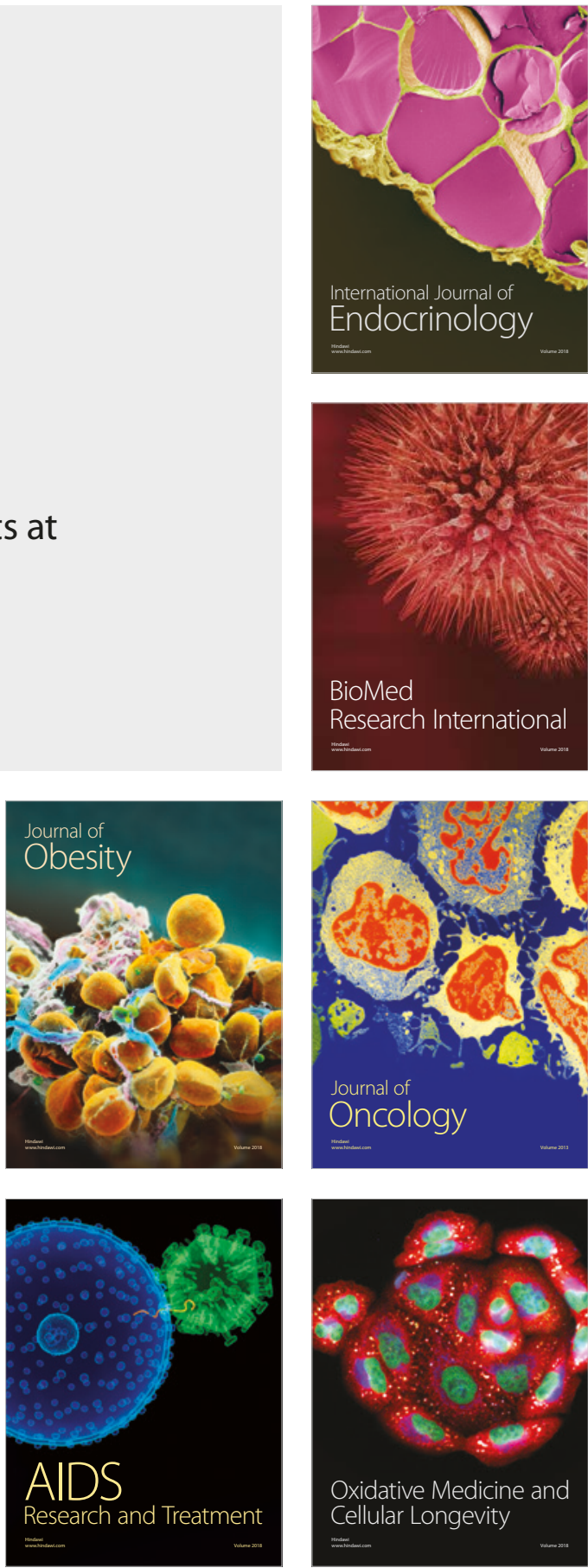